\title{
Gender differences in organ involvement and survival in systemic sclerosis - experience of a EUSTAR center
}

\author{
Laura Groseanu ${ }^{1,2}$, Andreea Petre', Andra Balanescu ${ }^{1,2}$, Violeta Bojinca ${ }^{1,2}$, \\ Daniela Opris-Belinski ${ }^{1,2}$, Florian Berghea ${ }^{1,2}$, Ioana Saulescu ${ }^{1,2}$, Diana Mazilu ${ }^{1,2}$, \\ Sanziana Daia Iliescu $\mathrm{u}^{1,2}$, Andreea Borangi, ${ }^{1,2}$, Cosmin Constantinescu, ${ }^{1,2}$, \\ Claudia Cobilinschi ${ }^{1,2}$, Maria Magdalena Negru ${ }^{1,2}$, Mihai Abobului1,2, \\ Ruxandra Ionescu, ${ }^{1,2}$ \\ 1"Sf. Maria“ Clinical Hospital, Department of Internal Medicine and Rheumatology, \\ Bucharest, Romania \\ 2"Carol Davila" University of Medicine and Pharmacy, Bucharest, Romania
}

\begin{abstract}
Introduction. The low overall prevalence of systemic sclerosis (SSc) and the low proportion of male patients have resulted in a scarcity of studies assessing sex differences in SSc patients, and contradictory results have often been observed.

Material and method. We performed a retrospective observational study using data extract from the EULAR scleroderma trials and research (EUSTAR) cohort 096 . We looked at sex influence on disease characteristics at baseline and then focused on patients with at least 2 years of follow-up to estimate the effects of sex on disease progression and survival.

Results. 173 patients with SSc were available for the baseline analyses. In the longitudinal analysis after a mean follow-up of 3.5 $( \pm 0.65)$ years, male sex was associated with a higher risk of scleroderma renal crisis (OR:9.45 (1.49 to 59.69); $p=0.004$ ), digital contractures (OR:8.2 (3.1 to 21.9); $p$ < 0.001), arrhythmias (OR: 3.37 (1.36 to 8.34); $p$ $=0.006$ ), pulmonary fibrosis (OR: $3.56,(1.51$ to 8.41$) ; p=0.003)$, pulmonary hypertension (OR: 3.01 (1.19 to 7.59); $p=0.016)$, severe vascular involvement (OR:2.86, (1.22 to 6.73); $p=0.013)$ and low ventricular ejection fraction (OR: $2.84,(1.2$ to 6.73$) ; p=0.014)$. Males had significantly reduced survival time after diagnosis $(p=0.004)$. The most frequent causes of death were scleroderma renal crisis in males and pulmonary hypertension in females. Conclusions. Although more common in women, SSc appears as strikingly more severe in men. Our results demonstrate a higher risk of severe organ involvement and poor prognosis in men. These results raise the point of including sex in the management and the decision-making process.
\end{abstract}

Keywords: systemic sclerosis, prevalence, gender differences, organ involvement, survival

\section{INTRODUCTION}

The cause of systemic sclerosis (SSc) is still unkown but hormonal, genetic, and environmental exposure factors have different effects on the clinical phenotype [1]. Evidence for the role of sex in the clinical manifestations of SSc in patients is scarce [1]. There were three recent multicentre studies assessing clinical differences between men and women with SSc: the Toronto Systemic sclerosis Program, the EULAR Scleroderma Trial and Research Group (EUSTAR) cohort and the Spanish RESCLE cohort
[2.3.4]. Also, Ferri et al. in 2002 evaluated differences by gender in some clinical, analytical and prognostic aspects of their series of 1012 patients belonging to 3 Italian centres [5]. These studies yielded mixed results in terms of sex predisposition for relevant clinical manifestations and survival [2-5].

\section{AIM \\ The objective of this study is to examine gender dif- ferences in a single EUSTAR center SSc cohort which has detailed clinical and laboratory data, and longitudi-}


nal follow-up including the presence and severity of organ system involvement and survival status.

\section{MATERIAL AND METHODS}

The EUSTAR database for center 096 was used to extract data from SSc patients evaluated during 20032018. Data included demographic features, disease subtype (diffuse cutaneous [dc] vs. limited cutaneous [lc]), smoking status, tests for specific organ system involvement, organ system involvement severity (severe and/or end-stage) using the revised Medsger severity score for SSc [6] and survival. First visit and all available follow-up visit data were examined. SSc was classified as dc (skin thickening proximal to the elbows or knees at any time during the illness) or lc (skin thickening only distal to the elbows or knees, face acceptable) [7].

An organ system was considered to be involved if the following features were documented at any time during the course of the illness and not attributable to other diseases. Some of these definitions were modified from a prior publication [4].

1. peripheral blood vessels: Raynaud phenomenon, digital pitting scars

2. skin: any thickening according to the modified Rodnan skin scoring (mRSS) system [8]

3. joints or tendons: joint swelling or contractures, fingertip-to-palm distance $>1.9 \mathrm{~cm}$ in full active flexion, or palpable tendon or bursal friction rubs

4. skeletal muscle: proximal muscle weakness on physical examination and any one of the following: elevated serum creatine kinase level, myopathic changes on electromyography or inflammation on muscle biopsy

5. gastrointestinal tract: any of the following: esophageal hypomotility (by barium swallow or manometry), esophageal stricture, radiographic evidence of hypomotility of the small intestine, wide-mouth colonic sacculations, or malabsorption syndrome

6. lung: (a) interstitial lung disease (ILD): pulmonary fibrosis (PF) on chest radiograph or computerized tomography of the lungs; (b) "intrinsic" pulmonary arterial hypertension (PAH): mean PA pressure $>25 \mathrm{mmHg}$ on right heart catheterization or estimated PA systolic pressure $>45 \mathrm{mmHg}$ on echocardiogram and the clinical diagnosis of PAH made by a cardiologist.

7. heart: left-sided heart failure (clinical) or estimated ejection fraction $(\mathrm{EF})<45 \%$, pericarditis, or arrhythmia requiring treatment
8. kidney: scleroderma renal crisis (SRC) - new malignant hypertension with a serum creatinine level of $<2.9 \mathrm{mg} / \mathrm{dl}$ at any time).

The severity of organ system involvement was defined as described previously [4.6]. Severe involvement was defined as either grade 3 (severe) or grade 4 (end-stage) according to the revised Medsger severity index score for SSc [6]. Grade 3 or 4 severity for each organ system was defined as follows:

1. peripheral blood vessels: presence of digital tip ulcers or gangrene

2. skin: $m R S S>30$

3. joints or tendons: fingertip-to-palm distance in full active flexion of $\geq 4.0 \mathrm{~cm}$

4. skeletal muscle: severe proximal muscle weakness on physical examination or muscle weakness requiring assistance with ambulation aids (e.g., crutches or cane)

5. gastrointestinal tract: malabsorption syndrome (physician judgment), episodes of pseudo-obstruction, hyperalimentation required, or death due to intestinal involvement

6. lung: (a) pulmonary fibrosis detected on radiograph in addition to at least one of the following: $\mathrm{FVC}<50 \%$ predicted, requirement for oxygen in those with ILD, lung transplantation performed for ILD, or death due to SSc-related ILD, or (b) pulmonary arterial hypertension (PAH) (not secondary to pulmonary fibrosis) with estimated peak PA systolic pressure $\geq 65 \mathrm{mmHg}$ on echocardiography or measured by right heart catheterization, requirement for oxygen due to SSc-related PAH, or death due to SSc-related PAH

7. heart: one of the following: left-sided congestive heart failure due to $\mathrm{SSc}$, arrhythmia requiring treatment, $\mathrm{EF}<40 \%$, heart transplantation performed for SSc myocardial disease, or death due to SSc-related heart disease

8. kidney: SRC - new malignant hypertension with a serum creatinine level of $\geq 3.0 \mathrm{mg} / \mathrm{dl}$ at any time, SRC with requirement for dialysis, renal transplantation performed for SSc-related renal disease, or death due to SSc-related renal disease.

Periungual capillaroscopy was performed, and the systemic sclerosis patterns obtained were classified according to the three types described by Cutolo [9]. 
Activity of the disease was evaluated using EScSG activity index [10].

\section{Statistical analysis}

Quantitative variables were described with mean \pm standard deviation (SD) or median and interquartile range for normally distributed or non-normally distributed continuous data, respectively. Qualitative variables were described with frequencies and percentages. Two-sample $t$ test or Mann-Whitney U-test was performed to determine differences between female and male groups for normally distributed or non-normally distributed continuous data, respectively. Pearson's chi-square or Fisher's exact test, as appropriate, were used to compare the frequency distribution of categorical variables between female and male groups. Kaplan-Meier survival curves from first SSc symptom onset, first SSc physician diagnosis and first clinic visit were calculated for 5, 10 and 15 years. Log-rank tests were performed to assess differences between survival rates. The proportional hazards assumption was tested for the variable of interest (sex) and was not violated. Survival curves adjusted for factors other than gender previously reported to be associated with increased mortality in SSc, including age, cutaneous subtype, smoking and involvement of the lung, heart or kidney, were generated from a Cox proportional hazards model.

\section{RESULTS}

\section{Impact of sex on phenotype at baseline}

A total of 173 consecutive new SSc patients were included (female to male ratio 5.65:1). Males were significantly older at symptom onset $(p=0.007)$ and at first center visit $(p=0.009)$. However, there were no differences regarding residence, disease duration at first visit or the interval between the onset of Raynaud syndrome and other non-Raynaud manifestations. Male SSc patients were significantly more likely to have ever smoked cigarettes $(65.5 \%$ vs. $34.5 \%, \mathrm{p}<0.001)$.

Males had predominantly diffuse skin involvement $(p=0.006)$ and higher mRSS $(p=0.004)$ compared to females. Although vascular involvement seems to be more frequent in men, the difference is not statistically significant. However, males more often had severe or end-stage peripheral vascular involvement $(50 \%$ vs. $25.9 \%, \mathrm{p}=0.01)$. Males often had digital contractures $(p=0.001)$, severe digital contractures $(p=0.001)$ and tendon friction rubs $(p=$
TABLE 1. Baseline characteristics and bivariate associations between sex and demographic characteristics at first center visit

\begin{tabular}{|c|c|c|c|}
\hline & $\begin{array}{l}\text { Females } \\
(n=147)\end{array}$ & $\begin{array}{l}\text { Males } \\
(n=26)\end{array}$ & $\begin{array}{l}\text { Significance } \\
\text { ( } p \text { value) }\end{array}$ \\
\hline $\begin{array}{l}\text { Age (yr), } \\
\text { mean+/-SD }\end{array}$ & & & \\
\hline At diagnosis & $45.65(13.04)$ & $52.96(11.75)$ & 0.007 \\
\hline At first center visit & $51.17(12.39)$ & $56.85(9.13)$ & 0.009 \\
\hline $\begin{array}{l}\text { Disease } \\
\text { duration }(m), \\
\text { mean+/-SD }\end{array}$ & $88.32(107.46)$ & $66.81(90.17)$ & NS \\
\hline $\begin{array}{l}\text { Residence, urban } \\
\mathrm{n}(\%)\end{array}$ & $88.32(107.46)$ & $66.81(90.17)$ & NS \\
\hline $\begin{array}{l}\text { Disease } \\
\text { classification, } \mathrm{n}(\%) \\
\text { Diffuse } \\
\text { Limited }\end{array}$ & $\begin{array}{l}58(39.5 \%) \\
83(56.5 \%)\end{array}$ & $\begin{array}{c}16(73.1 \%) \\
9(23.1 \%)\end{array}$ & 0.006 \\
\hline $\begin{array}{l}\text { Cigarette } \\
\text { smoking, n (\%) }\end{array}$ & $50(34.5 \%)$ & $17(65.5 \%)$ & 0.001 \\
\hline $\begin{array}{l}\text { Raynaud-non } \\
\text { Raynaud (m), } \\
\text { mean+/-SD }\end{array}$ & $30.04(47.07)$ & $17.85(28.41)$ & NS \\
\hline
\end{tabular}

Yr: years, SD: standard deviation, $m$ : months, $n$ : number, NS: not significant

0.044). Gastrointestinal involvement did not differ between groups. Males more often had interstitial lung disease ( $53.8 \%$ vs. $24.5 \%, \mathrm{p}=0.013)$ which was also more frequently severe or end-stage $(59.1 \%$ vs. $27.5 \%, p=0.003)$. The median of the expected values of forced vital capacity (FVC) $(p=0.004)$ and diffusing lung capacity for carbon monoxide (DLCO) $(\mathrm{p}=0.008)$ were significantly lower in men than in women. Cardiac involvement was more common in males, except for pericarditis: PAH $(34.6 \%$ vs. $12.9 \%, \mathrm{p}=0.018)$, arrhythmias (30\% vs. $15.6 \%, \mathrm{p}=$ $0.012), \mathrm{EF}<45 \%,(34.6 \%$ vs. $23.1 \%, \mathrm{p}=0.014) . \mathrm{SRC}$ was higher in males $(11.5 \%$ vs. $1.4 \%, \mathrm{p}=0.025)$. EScSG (European Scleroderma Study Group) disease activity scores were higher in males $(\mathrm{p}=0.001)$. Females associated more often anticentromere antibodies ( $38.09 \%$ vs. $11.53 \%, \mathrm{p}=0.008)$; males associated more often inflammatory syndrome $(65.38 \%$ vs. $38.77 \%, \mathrm{p}=0.011$ ).

No significant differences in capillaroscopic pattern were observed by gender.

\section{Impact of sex on disease outcomes}

154 patients had complete data at follow-up. Median monitoring interval was $3.50(0.65)$ years for males vs. 5.56(0.44) years for females; still the difference was not statistically significant $(\mathrm{p}=0.06)$.

For disease progression, we focused on severe organ involvement [new digital ulcers, new onset of $\mathrm{PAH}$, new onset of reduction of EF below $40 \%$, new 
TABLE 2. Baseline characteristics and bivariate associations between sex and clinical and paraclinic characteristics at first center visit

\begin{tabular}{|c|c|c|c|}
\hline Organ system involvement & Females $(n=147)$ & Males ( $n=26)$ & Significance ( $p$ value) \\
\hline Vascular involvement, $\mathrm{n}(\%)$ & $58(39.5 \%)$ & $15(57.7 \%)$ & 0.09 \\
\hline Severe vascular involvement, $\mathrm{n}(\%)$ & $38(25.9 \%)$ & $13(50 \%)$ & 0.013 \\
\hline mRSS, mean+/-SD & $9.29(5.45)$ & $12.19(5.96)$ & 0.004 \\
\hline Synovitis, n(\%) & $43(29.3 \%)$ & $9(34.6 \%)$ & NS \\
\hline Digital contractures, $\mathrm{n}(\%)$ & $48(32.7 \%)$ & $19(73.1 \%)$ & $<0.001$ \\
\hline Severe digital contractures, $\mathrm{n}(\%)$ & $12(8.2 \%)$ & $11(42.3 \%)$ & $<0.001$ \\
\hline $\begin{array}{l}\text { Muscle involvement, } \mathrm{n}(\%) \\
\text { Tendon friction rubs }\end{array}$ & $\begin{array}{l}19(6.8 \%) \\
13(8.8 \%\end{array}$ & $\begin{array}{l}2(7.7 \%) \\
6(23.1 \%)\end{array}$ & $\begin{array}{c}\text { NS } \\
0.044\end{array}$ \\
\hline Severe muscle involvement, $\mathrm{n}(\%)$ & $5(3.4 \%)$ & $0(0 \%)$ & NS \\
\hline GI involvement, $n(\%)$ & $10(66.7 \%)$ & $20(76.9 \%)$ & NS \\
\hline Severe GI involvement, $\mathrm{n}(\%)$ & $11(7.5 \%)$ & $10(3.8 \%)$ & NS \\
\hline Lung fibrosis, $n(\%)$ & $36(24.5 \%)$ & $14(53.8 \%)$ & 0.013 \\
\hline Severe lung involvement, $\mathrm{n}(\%)$ & $40(27.5 \%)$ & $15(59.1 \%)$ & 0.003 \\
\hline Pulmonary hypertension, $\mathrm{n}(\%)$ & $19(12.9 \%)$ & $9(34.6 \%)$ & 0.018 \\
\hline LV ejection fraction<45\%, $n(\%)$ & $34(23.1 \%)$ & $12(46.2 \%)$ & 0.014 \\
\hline Arrhythmias, n(\%) & $23(15.6 \%)$ & $8(30.3 \%)$ & 0.012 \\
\hline Pericarditis, n(\%) & $26(17.7 \%)$ & $5(19.2 \%)$ & NS \\
\hline Severe heart involvement, $\mathrm{n}(\%)$ & $13(8.8 \%)$ & $3(11.5 \%)$ & NS \\
\hline Scleroderma renal crisis, $\mathrm{n}(\%)$ & $20(1.4 \%)$ & $3(11.5 \%)$ & 0.025 \\
\hline EScSG disease activity score, $\mathrm{n}(\%)$ & $3.29(1.39)$ & $4.4(1.42)$ & 0.001 \\
\hline
\end{tabular}

\begin{tabular}{|l|c|c|c|}
\hline \multicolumn{1}{|c|}{ Paraclinic evaluations } & Females $(\mathbf{n}=\mathbf{1 4 7})$ & Males $(\mathbf{n}=\mathbf{2 6})$ & Significance (p value) \\
\hline Inflammatory syndrome, $\mathrm{n}(\%)$ & $56(38 \%)$ & $17(65.4 \%)$ & 0.011 \\
\hline Autoantibodies & & & NS \\
SCL70+ & $80(54.4 \%)$ & $3(73.1 \%)$ & 0.008 \\
ACA+ & $56(38.1 \%)$ & & \\
\hline Capillaroscopic pattern & & & \\
Early & & & \\
Active & & & NS \\
Late & $30.35(12.09)$ & $32.5(7.06)$ & 0.004 \\
\hline SPAP mean(SD), mmHg & $81.45(16.87)$ & $70.54(15.56)$ & 0.008 \\
\hline FVC (\%predicted), mean+/-SD & $68.02(16.87)$ & $57.81(16.99)$ & \\
\hline DLCO mean(SD), mean+/-SD & & & \\
\hline
\end{tabular}

n: number; Yr: year; m: months; mRSS: modified Rodnan skin score; SD-standard deviation; DLCO: diffusion capacity of the lung for carbon monoxide;GI-gastrointestinal; SCL70: scleroderma 70 autoantibody;ACA: anticentromere autoantibody; sPAP: estimated systolic pulmonary artery pressure; FVC: forced vital capacity; LV: left ventricle; EScSG- European Scleroderma Study Group; SD: standard deviation;

occurrence of SRC, new onset or worsening of pulmonary fibrosis on X-rays and/or high-resolution CT (HRCT) and deterioration of lung volume $(\geq 10 \%$ of FVC) during follow-up].

Gender differences were found for severe lung fibrosis before (odds ratio [OR]: 3.56, 95\% confidence interval $[\mathrm{CI}] 1.51-8.4, \mathrm{p}=0.003)$ and after adjustment by smoking status and disease subtype classification (OR: 2.14, 95\% CI 1.51-9.61, p < 0.001). Thus, males have higher odds of severe lung fibrosis no matter of smoking status and disease subtype classification.

In addition, in a univariate analysis, higher odds for a large number of characteristics were associated with male sex: a more severe vascular phenotype (OR: 2.86, 95\%CI (1.22-6.73), $\mathrm{p}=0.013)$, more severe digital contractures (OR: 5.59, 95\% CI (2.2-
14.22), $\mathrm{p}<0.001$ ), new onset of PH (OR: 3.01, 95\% CI $(1.19-7.59), \mathrm{p}=0.016)$, more frequent tendon friction rubs (OR: 2.61, 95\% CI (1.05-9.06), $\mathrm{p}=0.032)$, more arrhythmias (OR: $3.37,95 \% \mathrm{CI}(1.36-8.34), \mathrm{p}=$ $0.006)$ and new onset of $\mathrm{EF}<40 \%$ (OR: $2.84,95 \% \mathrm{CI}$ $(1.2-6.73), \mathrm{p}=0.014)$ and SRC (OR: 9.45, 95\% CI $(1.49-59.69), \mathrm{p}=0.004)$.

\section{Cumulative survival and causes of death}

The differences between groups at all stages of follow-up remained statistically significant except for the 15-year survival when taking into account the time from diagnosis and only the SSc related deaths. Overall the proportion of deaths in males was higher then in females, but not significant (20\% vs. $19 \%$, p $=0.194$ ). Still, males have worse unadjusted cumula- 


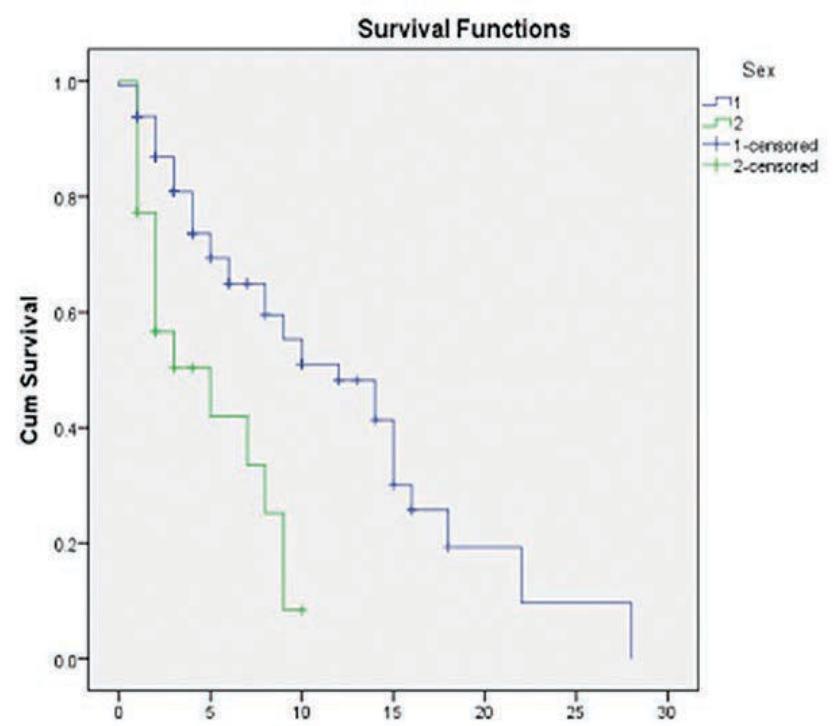

(a)

Log rank $=14.91, p<0.001 p=0.023$

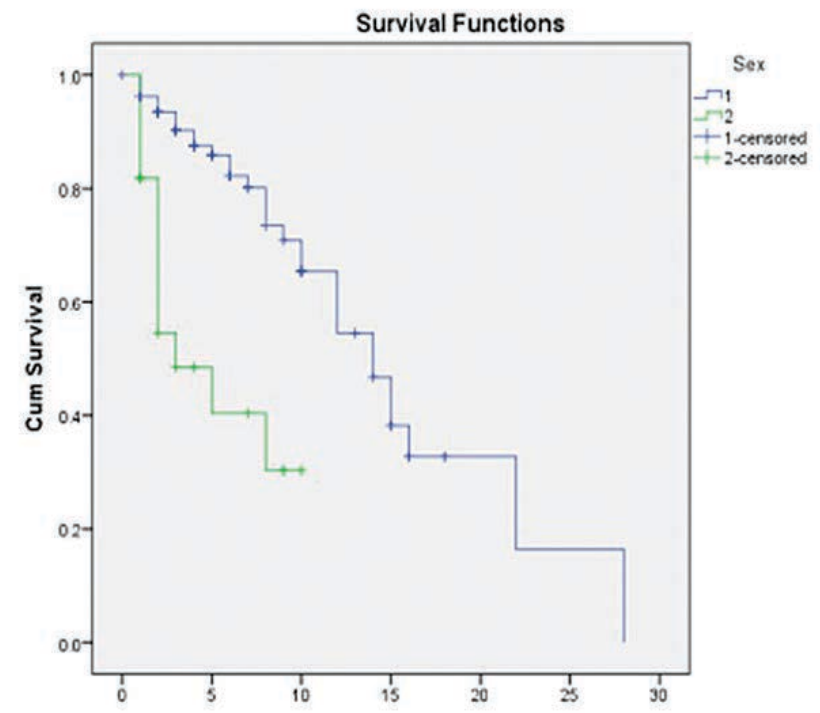

(c)

Log rank $=19.69, \mathrm{p}<0.001 \mathrm{p}=0.023$

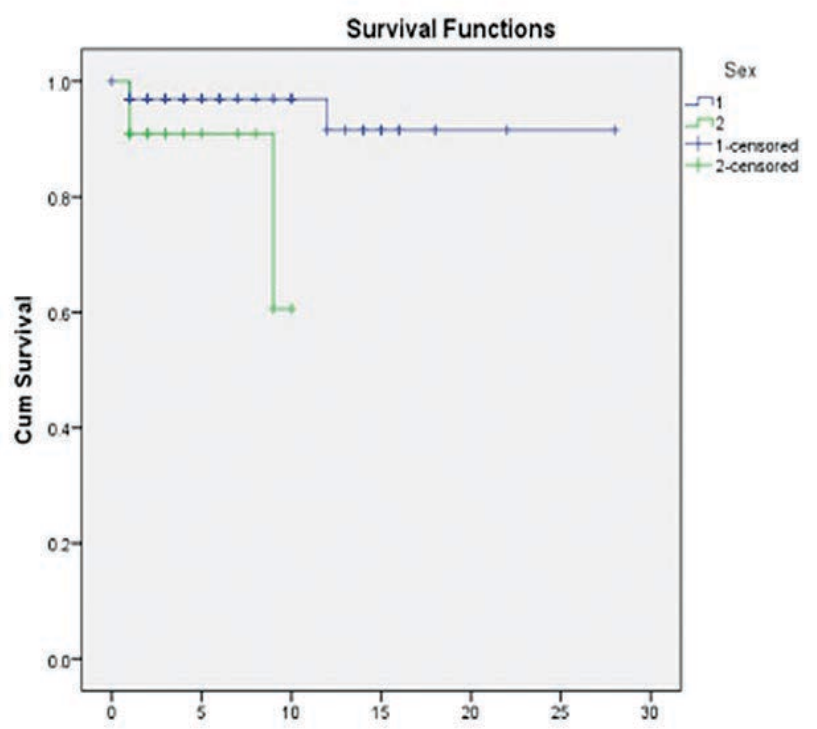

(b)

Log rank $=5.14, p=0.023$

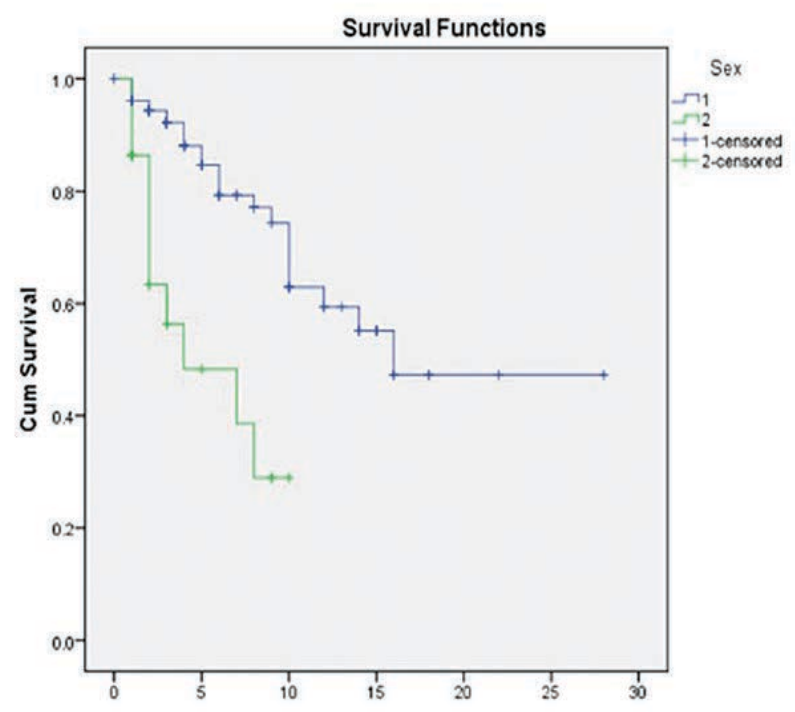

(d)

Log rank $=17.84, \mathrm{p}<0.001 \mathrm{p}=0.023$

FIGURE 1a,b,c,d. Cumulative risk for pulmonary fibrosis (a), scleroderma renal crisis (b), vascular involvement (c) and arrhythmias (d) from the time of first symptom in all females and males with systemic sclerosis

tive survival rates at 5 years $(93.33 \%$ vs. $77.7 \%$, HR $=4.33$, CI 95\% $1.05-17.77, \mathrm{p}=0.005)$ and at 10 years $(64.81 \%$ vs. $84.85 \%$, HR $=2.61$, CI95\% $1.08-17.38$, $\mathrm{p}=0.04)$ after diagnosis. The age at death did not differ between men and women, but the median survival interval after diagnosis was significantly shorter for males [5.22(4.17) years vs. 8.29(5.7)years, $\mathrm{p}=$ $0.002]$.

The distribution of causes of death was significantly different, primarily because PF and SRC are a relatively more frequent cause in males and $\mathrm{PH}$ in females (table 3). Smoking, immunological prophyle does not seem to be a predictor of death regarding to sex. The only negative prognostic factor associated with death in females was severe vascular involvement $(p=0.03)$. Male SSc patients with severe pulmonary involvement and severe cardiac involvement have significant lower survival then female patients $(p<0.001$, respectively $p=0.03)$. Although, data are not statistically significant, SRC might increase the risk of death in male patients as none of SRC patients survives at 3 years. When analysing the SSc-related 
TABLE 3. Cumulative survival and causes of death in male and female SSc patients

\begin{tabular}{|l|c|c|c|c|}
\hline & & & Unadjusted & Adjusted* \\
\hline 5 year CSR & & 77.78 & 0.005 & 0.005 \\
\hline 10 years CRS & 84.85 & 64.81 & 0.04 & 0.03 \\
\hline 15 years CRS & 69.21 & 64.81 & & 0.08 \\
\hline Causes of death & & & & \\
\hline Unknown & Females & Males & & \\
\hline Not SSc related & 14.3 & 0 & & \\
\hline SSc related & 14.3 & 0 & & \\
\hline Intrinsec PH & 75.1 & 100 & & \\
\hline Pulmonary Fibrosis & 25 & 0 & & \\
\hline SRC & 10.7 & 20 & NS & \\
\hline Cardiac & 14.2 & 40 & NS & \\
\hline Other & 14.3 & 20 & NS & \\
\hline
\end{tabular}

CSR - cumulative survival rate, SSC - systemic sclerosis, PH - pulmonary hypertension, SRC-scleroderma renal crisis * Adjusted for cutaneous subtype $(d c, l c)$

and unrelated causes of death separately, significant differences were observed: $100 \%$ of men died of SSc related cause, $76 \%$ of females died of SSc related causes.

\section{DISCUSSION}

Autoimmune diseases are more prevalent in women, as is the case with SSc. Previous studies demonstrated that estradiol promotes the development of a fibrotic phenotype, both in vitro and ex vivo in human skin [11]. In addition, serum estradiol levels are significantly elevated in postmenopausal female patients with early diffuse cutaneous SSc compared to healthy postmenopausal female controls [11]. As men age, their estrogen levels increase [11]. Since the men in our study are older at disease onset, they likely have elevated estrogen levels which contribute to the increased severity of disease.

In addition to hormonal status, the female preponderance in SSc is proposed to be due to genetic/epigenetic differences and $\mathrm{X}$ chromosome gene reactivation or skewed $\mathrm{X}$ chromosome inactivation (reviewed in D'Amico et al.) [12].

The objective of this study was to describe gender differences in SSc in a large single-center cohort. To our knowledge, the present study is the first to identify sex-related differencies in a Romanian cohort. Our analyse were comprehensive, analyzing demographic information, disease subtype, organ system involvement and severity, serum autoantibody profile, survival and causes of death. While there were many similarities when comparing the female with male cohort SSc patients, several key differences emerged, as illustrated in table 1 and 2. Our findings are consistent with other publications concluding that in $\mathrm{SSc}$ as in other related autoimmune diseases, male gender and dcSSc are poor prognostic factors [1-5].

In our cohort, the female to male ratio was 5.6:1. This is similar to, but slightly higher than, the previous estimates of $3: 1$ to $4: 1$ [3]. The men of the present cohort were older than women at disease onset, but the the interval to diagnosis was not longer then in females. Our findings are different from those reported from a large SSc cohort [1]. In the RESCLE cohort, it took more than twice as long to diagnose women with SSc than to diagnose men, consistent with data from the two previous multicentre studies[15.16].

There was no difference regarding the presence of antiSCL70 antibodies, but in the female group the prevalence of anticentromere antibodies was higher. This result is in line with previous studies [4] while others report no difference [17].

In our series, the presence of ulcers was not significantly different between the sexes, but males develop more severe vascular involvement $(\mathrm{p}=0.013)$. The same was observed in other single centre studies $[15,16]$. However, other groups have reported more distal vascular involvement in men [18.19], and the study by Manfredi et al., conducted in 219 Italian patients, identified the male gender as an independent risk factor for the appearance of skin ulcers over a follow-up period of 6 months [20].

In this study, male sex was identified as an independent predictor of new occurrence of $\mathrm{PH}$, severe heart dysfunction and arrhytmias during the followup, with OR equal to $3.01,3.37,2.84$ respectively. Male sex was independently associated with $\mathrm{PH}$, but was also predictive of new occurrence of $\mathrm{PH}$ during the follow-up. In a previous study on a large EU- 
STAR cohort, male sex was independently associated with PH [3]. However, our study might have been biased because $\mathrm{PH}$ was not confirmed in all cases by right heart catheterisation, which is the gold standard for the diagnosis. It is of interest to notice that usually idiopathic pulmonary arterial hypertension occurs more frequently in women.

ILD was more frequent in men in our group than in women at baseline; the median of the expected values of FVC and DLCO were significantly lower in men than in women. Males have higher odds $(\mathrm{OR}=$ $2.14, \mathrm{p}<0.001)$ of severe lung fibrosis when compared to females before and after adjustment for smoking status and disease subtype classification. This data are concordant with data coming from larger cohorts, as the RESCLE cohort (1). Moreover, in a recent multiliear variate analyse of EUSTAR database, male sex was proved to be an independent predictor of progressive lung disease [21]. Herein, male sex was identified as an independent predictor of new occurrence of heart dysfunction, arrhythmias and ILD during the follow-up. These results are of major interest since $\mathrm{PH}$, heart dysfunction along with lung fibrosis are the leading causes of death in SSc [22].

Another important characteristic of our study group is related to musculoskeletal involvement. Males have more digital contractures and tendon friction rubs (TFRs) at first center visit and have higher odds of developing severe digital contractures and more tendon friction rubs at follow-up $(\mathrm{OR}=8.25$, respectively 2.61). Patients with early diffuse SSc having one or more TFRs are at increased risk of developing renal, cardiac and gastrointestinal involvement before and after their first at Pittsburg Scleroderma Center visit, and have reduced survival [23]. A more recent analyse of a large EUSTAR cohort confirmed TFRs as an independent predictor of scleroderma renal crisis [24].

Early studies suggested that African-American patients and males were more likely to develop scleroderma renal crisis but later studies have not born this out [25]. However, male gender is considered a risk factors for poor outcome in scleroderma renal crisis [26]. Males in our cohort have a higher incidence of SRC at follow-up and SRC is the major cause of death.

Several observational studies indicated that males had worse survival rates than females [27-31]while other studies report no statistical differences [32-34]. In our study, mortality rate at 15 years was similar between men and females. However, a higher per- centage of men died in a shorter period of follow-up because the onset of symptoms in men was later, despite the age of death being the same in men and women. The most common cause of death in men and women was SRC in men (40\%) and $\mathrm{PH}$ in women $(25 \%)$. There were also sex differences in the proportion of deaths due to ILD and cardiac . It is also important to note that every man who died due to $\mathrm{PH}$ had associated ILD. Our study found differences between sexes in short-term survival, and as time progressed, the survival differences became dimished. When comparing the Kaplan-Meier survival curves, it appears that the survival difference between males and females began to decrease at 15 years of disease activity. A study of the data extracted from the EUSTAR cohort showed that sex survival differences in the Kaplan Meier curves for overall death disappeared when they were further analysed for SSc-related deaths [3]. Their mean follow-up period was only 5 years, which is very limited in regard to assessing differences in cumulative survival time.

In the RESCLE cohort, predictive factors for overall mortality from the date of onset were, in order of relevance, dcSSc, ILD, presence of digital ulcers and tendon friction rubs, male sex and older age at onset [1]. In the meta-analysis conducted by Rubio et al. in 2014, the ILD showed an overall HR of 2.89 for unfavourable outcomes in patients with SSc [36]. In our series the main factors for poor prognosis in patients with SSc, were ILD and cardiac involvement.

Results obtained through the largest worldwide database showed a higher mortality in affected men with 1.8-fold more deaths in men compared with women [3]. In our study mortality rate at 15 years was not significantly different between men and women, but the survival interval after diagnosis is shorter in males $(p=0.04)$. Several hypotheses might be driven to explain this discrepancy. None of the male patients with lung involvement survives after 10 years, none of the male patients with SRC survives after 5 years so the sample size of men at 15 years to compare data. When we stratified mortality causes, there were no significant differences between men and women, except for the fact that all men died od SSc related causes.

The strength of our study is the length of time over which patients were followed, long enough to assess differences in survival curves. International registries have utility to understand the overall behaviour of SSc, but national registries are essential to define the behavior of systemic sclerosis in a specific 
population and can reveal variations that arise from environmental or genetic conditions. A limitation of our study is the small number of patients. Both right heart catheterization and echocardiography were used for inclusion of patients with $\mathrm{PH}$; therefore this diagnosis of PH may have been overestimated in our study. This may affect comparison of our results to other SSc centers. For our study, we chose time 0 for the survival analysis as "time from diagnosis" because we could then be more precise about the starting date (less susceptible to recall bias), apply it uniformly to the cohort, and be sure that the patient had the diagnosis of SSc. This may have biased our results to shorter disease durations than would have been estimated using time of onset of Raynaud or first non-Raynaud phenomenon.

Conflict of interest: none declared

Financial support: none declared

\section{REFERENCES}

1. Freire M, Rivera A, Sopeña B, Tolosa Vilella C, Guillén-Del Castillo A, et al.; RESCLE investigators, Autoimmune Diseases Study Group (GEAS). Clinical and epidemiological differences between men and women with systemic sclerosis: a study in a Spanish systemic sclerosis cohort and literature review. Clin Exp Rheumatol. 2017 Sep-Oct;35 Suppl 106(4):89-97.

2. Hussein $\mathrm{H}$, Lee $\mathrm{P}$, Chau $\mathrm{C}$, Johnson Sr. The effect of male sex on survival in systemic sclerosis. J Rheumatol. 2014;41:2193-200.

3. Elhai M, Avouac J, Walker UA, Matucci-Cerinic M, Riemekasten $G$, Airò $P$, et al. A gender gap in primary and secondary heart dysfunctions in systemic sclerosis: a EUSTAR prospective study. Ann Rheum Dis. 2016;75(1):163-9.

4. Peoples C, Medsger TA, Lucas M, Rosario BI, Feghali-Bostwick CA. Gender differences in systemic sclerosis: relationship to clinical features, serologic status and outcomes. J Scleroderma Relat Disord. 2016;1(2):177-204.

5. Ferri C, Valentini G, Cozzi F, Sebastiani M, Michelassi C, et al. Systemic sclerosis: demographic, clinical, and serologic features and survival in 1012 Italian patients. Medicine (Baltimore). 2002;81(2):139-53.

6. Bombardieri S, Medsger TA Jr, Silman AJ, Valentini G. The assessment of the patient with systemic sclerosis. Introduction. Clin Exp Rheumatol. 2003;21(3 Suppl 29):S2-4.

7. Clements PJ, Feghali CA. Cutaneous involvement in systemic sclerosis. Philadelphia: Lippincott Williams \& Wilkins; 2004.

8. Clements P, Lachenbruch P, Siebold J, White B, Weiner S, Martin R, Weinstein A, Weisman M, Mayes M, Collier D, et al. Inter and intraobserver variability of total skin thickness score (modified Rodnan TSS) in systemic sclerosis. J Rheumatol. 1995 Jul;22(7):1281-5.

9. Cutolo M, Pizzorni C, Secchi ME, Sulli A. Capillaroscopy. Best Pract Res Clin Rheumatol. 2008 Dec;22(6):1093-108.

10. Valentini G, D'Angelo S, Della Rossa A, Bencivelli W, Bombardieri S. European Scleroderma Study Group to define disease activity criteria for systemic sclerosis. IV. Assessment of skin thickening by modified Rodnan skin score. Ann Rheum Dis. 2003 Sep;62(9):904-5.

11. Soldano S, Montagna P, Villaggio B, Parodi A, Gianotti G, et al. Endothelin and sex hormones modulate the fibronectin synthesis by cultured human skin scleroderma fibroblasts. Ann Rheum Dis. 2009;68:599-602.

12. D'amico F, Skarmoutsou E, Mazzarino MC. The sex bias in systemic sclerosis: on the possible mechanisms underlying the female disease preponderance. Clin Rev Allergy Immunol. 2014;47:334-43.

13. Roberts-Thomson PJ, Jones M, Hakendorf $P$, Kencana Dharmapatni AA, Walker JG, MacFarlane JG, Smith MD, Ahern MJ. Scleroderma

\section{CONCLUSIONS}

In females, systemic sclerosis ( $\mathrm{SSc}$ ) occurs at a younger age and is more likely to be of the limited cutaneous (lc) subtype with anti-centromere antibody and improved survival. In contrast, male SSc patients present at an older age, are more likely to be cigarette smokers, have diffuse cutaneous (dc) involvement, more frequent digital ulcers, pulmonary fibrosis, cardiac involvement and reduced survival. Knowledge of the distinguishing sex related features in SSc is very important, not only because it allows for better understanding of the pathogenesis of this complex disease but also because it helps establish monitoring protocols and specific treatments adapted to the needs of each group and to establish prognostic subgroups.

in South Australia: epidemiological observations of possible pathogenic significance. Intern Med J. 2001 May-Jun;31(4):220-9.

14. Jablonska S, Blaszcyk M. Connective tissue diseases. In: Parish LC, Brenner S, Ramos e Silva M, Parish JL (eds.). Women's dermatology: from infancy to maturity. New York: Informa Healthcare 2001;205-16.

15. Joven BE, Almodovar R, Carmona L, Carreira PE. Survival, causes of death, and risk factors associated with mortality in Spanish systemic sclerosis patients: results from a single university hospital. Semin Arthritis Rheum. 2010;39:285-93.

16. Kuo CF, See LC, Yu KH, Chou IJ, Tseng WY, et al. Epidemiology and mortality of systemic sclerosis: a nationwide population study in Taiwan. Scand J Rheumatol. 2011;40:373-8.

17. Wielosz E, Majdan M, Dryglewska M, Suszek D. Comparison of clinical and serological parameters in female and male patients with systemic sclerosis. Reumatologia. 2015;53(6):315-320.

18. Hachulla E, Clerson P, Launay D, Lambert M, Morell-Dubois S, et al. Natural history of ischemic digital ulcers in systemic sclerosis: Single-center retrospective longitudinal study. J Rheumatol. 2007;34:2423-30.

19. Steen V, Denton CP, Pope JE, Matucci-Cerinic M. Digital ulcers: overt vascular disease in systemic sclerosis. Rheumatology (Oxford). 2009 Jun;48 Suppl 3:iii19-24.

20. Manfredi A, Sebastiani M, Carraro V, ludici M, Bocci M, et al. Prediction risk chart for scleroderma digital ulcers: a composite predictive model based on capillaroscopic, demographic and clinico-serological parameters. Clin Hemorheol Microcirc. 2015;59:133-43.

21. Hoffmann-Vold AM, Allanore Y, Alves M, Brunborg C, Airó P, Ananieva LP, et al.; EUSTAR collaborators. Progressive interstitial lung disease in patients with systemic sclerosis-associated interstitial lung disease in the EUSTAR database. Ann Rheum Dis. 2021 Feb;80(2):219-227.

22. Tyndall AJ, Bannert B, Vonk M, Airò P, Cozzi F, et al. Causes and risk factors for death in systemic sclerosis: a study from the EULAR Scleroderma Trials and Research (EUSTAR) database. Ann Rheum Dis. 2010;69:1809-15.

23. Khanna PP, Furst DE, Clements PJ, Maranian P, Indulkar L, Khanna D; D-Penicillamine Investigators. Tendon friction rubs in early diffuse systemic sclerosis: prevalence, characteristics and longitudinal changes in a randomized controlled trial. Rheumatology. 2010;49(5):955-959.

24. Doré A, Lucas M, Ivanco D, Medsger TA Jr, Domsic RT. Significance of palpable tendon friction rubs in early diffuse cutaneous systemic sclerosis. Arthritis Care Res (Hoboken). 2013;65(8):1385-1389. 
25. Vaidya PN, Basyal B, Finnigan NA. Scleroderma And Renal Crisis. [Updated 2020 Jul 11]. In: StatPearls [Internet]. Treasure Island (FL): StatPearls Publishing; 2020.

26. Steen VD. Kidney involvement in systemic sclerosis. Presse Med. 2014;43(10 Pt 2):e305-14.

27. Nguyen C, Bérezné A, Baubet T, Mestre-Stanislas C, Rannou F, Papelard A, Morell-Dubois S, Revel M, Guillevin L, Poiraudeau S, Mouthon L; Groupe Français de Recherche sur la Sclérodermie. Association of gender with clinical expression, quality of life, disability, and depression and anxiety in patients with systemic sclerosis. PLoS One. 2011 Mar 9;6(3):e17551.

28. Piper WN, Helwig EB. Progressive systemic sclerosis; visceral manifestations in generalized scleroderma. AMA Arch Derm. 1955;72:535-46.

29. Hissaria P, Lester S, Hakendorf P, Woodman R, Patterson K, Hill $\mathrm{C}$, et al. Survival in scleroderma: results from the population-based South Australian Register. Intern Med J. 2011;1:381-90.
30. Hashimoto A, Tejima S, Tono T, Suzuki M, Tanaka S, Matsui T, et al. Predictors of survival and causes of death in Japanese patients with systemic sclerosis. J Rheumatol. 2011;38:1931-9.

31. Fransen J, Popa-Diaconu D, Hesselstrand R, Carreira P, Valentini $G$, et al. Clinical prediction of 5 -year survival in systemic sclerosis: validation of a simple prognostic model in EUSTAR centres. Ann Rheum Dis. 2011;70:1788-92.

32. Altman RD, Medsger TA, Bloch DA, Michel BA. Predictors of survival in systemic sclerosis (scleroderma). Arthritis Rheum. 1991;34:403-13.

33. Geirsson AJ, Wollheim FA, Akesson A. Disease severity of 100 patients with systemic sclerosis over a period of 14 years: using a modified Medsger scale. Ann Rheum Dis. 2001;60:1117-22.

34. Simeón CP, Castro-Guardiola A, Fonollosa V, Armadans L, Clemente C, Solans R, et al. Systemic sclerosis in men: clinical and immunological differences. Br J Rheumatol. 1996;35:910-1.

35. Rubio-Rivas M, Royo C, Simeón CP, Corbella X, Fonollosa V. Mortality and survival in systemic sclerosis: systematic review and meta-analysis. Semin Arthritis Rheum. 2014;44(2):208-19. 